\title{
A longitudinal study on morpho-genetic diversity of pathogenic Rhizoctonia solani from sugar beet and dry beans of western Nebraska
}

Saurav Das, T. Plyler-Harveson, Dipak K. Santra* (D, Bijesh Maharjan, Kathy A. Nielson and Robert M. Harveson

\begin{abstract}
Background: Root and stem rot caused by Rhizoctonia solani is a serious fungal disease of sugar beet and dry bean production in Nebraska. Rhizoctonia root rot and crown rot in sugar beet and dry bean have reduced the yield significantly and has also created problems in storage. The objective of this study was to analyze morpho-genetic diversity of 38 Rhizoctonia solani isolates from sugar beet and dry bean fields in western Nebraska collected over 10 years. Morphological features and ISSR-based DNA markers were used to study the morphogenetic diversity.

Results: Fungal colonies were morphologically diverse in shapes, aerial hyphae formation, colony, and sclerotia color. Marker analysis using 19 polymorphic ISSR markers showed polymorphic bands ranged from 15 to 28 with molecular weight of $100 \mathrm{bp}$ to $3 \mathrm{~kb}$. Polymorphic loci ranged from $43.26-92.88 \%$. Nei genetic distance within the population ranged from 0.03-0.09 and Shannon diversity index varied from 0.24-0.28. AMOVA analysis based on DPT values showed $87 \%$ variation within and $13 \%$ among the population with statistical significance $(p<0.05)$. Majority of the isolates from sugar beet showed nearby association within the population. A significant number of isolates showed similarity with isolates of both the crops suggesting their broad pathogenicity. Isolates were grouped into three different clusters in UPGMA based cluster analysis using marker information. Interestingly, there was no geographical correlation among the isolates. Principal component analysis showed randomized distribution of isolates from the same geographical origin. Identities of the isolates were confirmed by both ITS-rDNA sequences and pathogenicity tests.
\end{abstract}

Conclusion: Identification and categorization of the pathogen will be helpful in designing integrated disease management guidelines for sugar beet and dry beans of mid western America.

Keywords: Rhizoctonia solani, Sugar beet, Dry bean, DNA marker, Nebraska, USA

\footnotetext{
*Correspondence: dsantra2@unl.edu

Panhandle Research and Extension Centre, University of Nebraska-Lincoln,

Scottsbluff, NE, USA
}

(c) The Author(s). 2020 Open Access This article is licensed under a Creative Commons Attribution 4.0 International License, which permits use, sharing, adaptation, distribution and reproduction in any medium or format, as long as you give appropriate credit to the original author(s) and the source, provide a link to the Creative Commons licence, and indicate if changes were made. The images or other third party material in this article are included in the article's Creative Commons licence, unless indicated otherwise in a credit line to the material. If material is not included in the article's Creative Commons licence and your intended use is not permitted by statutory regulation or exceeds the permitted use, you will need to obtain permission directly from the copyright holder. To view a copy of this licence, visit http://creativecommons.org/licenses/by/4.0/. The Creative Commons Public Domain Dedication waiver (http://creativecommons.org/publicdomain/zero/1.0/) applies to the data made available in this article, unless otherwise stated in a credit line to the data. 


\section{Background}

Rhizoctonia solani is a polyphagous plant pathogen with worldwide distribution. It is a soil-borne pathogen and known for severe plant diseases like collar rot, root rot, damping off and wire stem [1]. The fungus survives on the infected plant debris and acts as an inoculum for the susceptible crops like sugar beet (Beta vulgaris subsp. vulgaris) [2], dry beans (Phaseolus vulgaris) [2], potato (Solanum tuberosum) [3], and soybean (Glycine max) [4]. It is a major problem for the sugar beet and dry bean producers of western Nebraska. Total production acreage of dry bean and sugar beet crops in Nebraska are 45,500 and 140,000-200,000 acres respectively. However, every year Rhizoctonia root rot and crown rot in sugar beet (Fig. 1b) and dry bean (Fig. 1a) have reduced the yield significantly and also created problems in storage. It has been estimated that on average $20 \%$ of annual sugar beet yield loss is due to the Rhizoctonia root and crown rot, and even in some rare scenarios $30-60 \%$ to complete loss of the crop has also been observed [5]. In Nebraska, a total of 52 and $42 \%$ of yield reduction can be observed in case of dry bean variety viz. Great Northern bean and Pinto bean, respectively due to Rhizoctonia root and crown rot [6].

$R$. solani occurs in varying levels of morphogenetic diversity. Cultural appearance, anastomosis, virulence, and physiology are different among different strains. Many scientific attempts have been made to categorize the $R$. solani isolates based on morphological, physiological and pathological differences. The most accepted grouping of $R$. solani is based on the formation of anastomosis or hyphal fusion [7, 8]. There are now 14 anastomosis groups (AG), several of which are divided into subgroups [9]. But the presence of more than one AG and occasional loss of anastomosis ability always complicated the identification and characterization of Rhizoctonia sp. Further, several studies have also indicated distinct pathogenesis even within the same AG groups [7, 10]. Morphological characteristics are further influenced by the culture conditions, which makes it more difficult to characterize and categorize the isolates. The problem associated with characterization can be better addressed with the DNA-based molecular studies [10-13]. Several DNA-based markers were used to analyze the genetic diversity of $R$. solani. These are genome sequence complementary analysis [14], random amplified polymorphic DNA (RAPD) $[10,13,15]$, amplified fragment length polymorphism (AFLP) [16], simple sequence repeats (SSR) [17], and inter-simple sequence repeats (ISSR) [13, 18-21].

ISSR markers were developed in 1994 and since then these were widely used for rapid differentiation among the closely related species. The technique involves the amplification of the inter-region between two SSR regions with a primer of $16-18$ bp long and with a flanking region of nucleotides at the $3^{\prime}$ or $5^{\prime}$ end. ISSR analysis is simple and less expensive than RAPD and AFLP. It can be used to assess the genetic diversity of a large number of phytopathogens within relatively less time and with high reproducibility [15]. Several researchers used dominant nature of the ISSR to establish the genetic variations and relationships among the $R$. solani isolates of different geographic regions and within the same anastomosis group [10, 13, 15].

Rhizoctonia root, stem, and crown rot are common in sugar beet and dry bean fields every year across western Nebraska. Our hypothesis was that isolates collected from two different crops could be different and also isolates collected from the same crop across the years and geographic region could be different. The objective of this study was to determine the morpho-genetic diversity among $R$. solani isolates of sugar beet (RZ_SB) and dry bean (RZ-DB) from western Nebraska. The genetic diversity was assessed with 19 polymorphic ISSR markers using a collection of isolates from the central great plains.

\section{Results \\ Morphological diversity}

A total of 38 fungal colonies of the RZ_SB and RZ_DB isolates were established in laboratory and these were used for studying morphological characteristics. All the 38 isolates showed distinctive morphological variation in their appearance. Colony morphology colors varied from dark brown to light brown and light tan (Fig. 1c), sclerotia and presence of aerial hyphae (Fig. 1d, Table 1). Correlation analysis showed a positive correlation within the isolates of same crops. The isolates from sugar beet showed a positive correlation with sugar beet isolates and dry beans with dry bean isolates (Fig. 2). There was high positive correlation within the isolates of sugar beets, RZ_SB16, RZ_SB56, RZ_SB373, RZ_SB387, RZ_SB389, RZ_SB364, RZ_391，RZ_332 $(r=1.00 / 1.00, p<0.0001)$. Similarly, the isolates from dry beans R_DB10, RZ-DB305, RZ_DB386, RZ_DB116, RZ_DB336, RZ_DB360, RZ_DB379 showed significantly high correlation with each other $(r=1.00 / 1.00, p<$ $0.0001)$. Though most of the isolates showed morphological correlation within the isolates of same crop there was also positive cross crop correlation with statistical significance but at a lower degree. Isolates $\mathrm{RZ}$ DB22 showed correlation with RZ_SB358 $(\mathrm{r}=0.77 / 1.00$, $p<0.01)$ and RZ_SB359 $(r=0.63 / 1.00, p<0.05), \mathrm{RZ}$ DB305 with RZ-SB375 $(r=0.67 / 1.00, p<0.05)$ (Fig. 2) (Supplementary file: Table: T1). There was no correlation between the isolates from the same geographical origin and year of origin. 


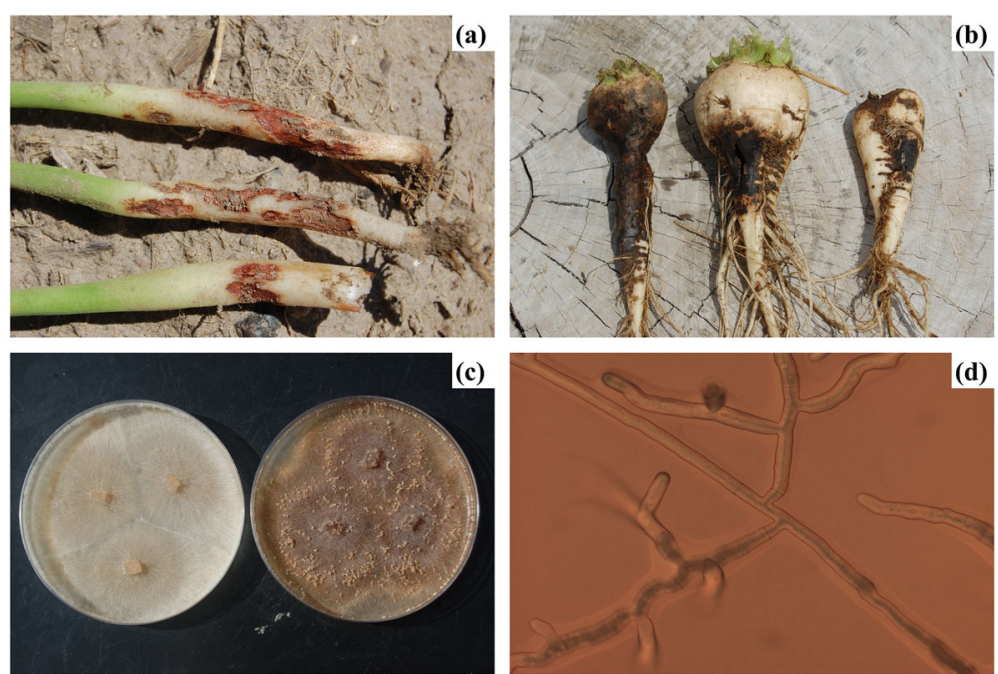

Fig. 1 a Dry bean root rot (b) Sugar beet root rot (c) PDA culture plate (d) microscopic hyphal structure

\section{Identity of isolates}

ITS-rDNA sequence of the 38 test isolates ( 9 dry bean, 29 sugar beet) matched with that of 3 check isolates (RZ_SBC23, RZ_SBC28, and RZ_SBC51) and all these 41 sequences matched with Rhizoctonia solani (or Rhizoctonia only) based on Genebank data base (Table 1).

Infection of sugar beet seedlings by the 29 sugar beet isolates and the three check isolates ( $R Z_{-} S B C 23, R Z_{-}$ $S B C 28$, and $R Z$ SBC51) in the greenhouse produced similar symptom, which was similar to characteristic symptom of Rhizoctonia root rot of sugar beet (Fig. 1b). Infection of dry bean seedlings by the 9 dry bean isolates in the greenhouse produced symptom, which was similar to characteristic symptom of Rhizoctonia root rot of dry bean (Fig. 1a).

\section{Genetic diversity}

A total of 50 UBC primers were screened and 19 primers were selected based on their $100 \%$ polymorphism index. A total of 396 alleles were identified from 41 isolates (representative gel image at Fig. 3). An average number of loci per primer was 20.84 and band size ranged from $100 \mathrm{bp}$ to $3 \mathrm{~kb}$. The primer UBC 889 produced the highest number of polymorphic loci (29) followed by UBC 808 (27), UBC 809 (26) and UBC 812(25) (Table 2). The Shannon information index (I) varied from $0.235-0.280$ with an average of 0.251 . The percentage of polymorphic loci (\% P) ranged from 43.26-92.88\%. The highest \% polymorphic loci (92.88\%) was observed within the dry bean isolates (population 2) (Table 3). The Nei genetic distance within the population ranged from $0.033-0.083$ with an average of 0.51 .

Cluster analysis based on the UPGMA method produced three distinct clusters. The first cluster majorly represented the isolates from dry bean (RZ_DB 116, RZ_386, RZ_DB336, RZ_DB10, RZ_DB305, and RZ_ DB360) showing their genetic similarity. However, four sugar beet isolates (RZ_SB373, RZ_374, RZ_375, and RZ_SB38) also showed significant similarities with dry bean isolates in the first cluster. The second cluster included only sugar beet isolates viz. RZ_SBC51, RZ_ SB349, RZ_B358, RZ_SB37, RZ-SB1, RZ_SB389, RZ_ SB391, RZ_SB16, RZ_SB56, RZ_SB338, RZ_SBC23, RZ_SB359, RZ_SB387, RZ_SB332, RZ_SB364. While the third cluster showed cross relation among dry bean and sugar beet isolates (Fig. 4). Dry bean isolates like RZ_DB22, RZ_DB222, and RZ_DB379 showed genetic relatedness with sugar beet isolates RZ_SB330, RZ_ SB188, and RZ_SB54 in the third cluster. Isolates like RZ_SB374 and RZ_SB375 (with $\mathrm{au}=99 \%$ and bp $=$ 97\%) which were isolated in the year of 2008 from Scottsbluff showed similarity in genetic makeup. Isolates like RZ_SB332 (2005) showed similar genetics with isolates RZ_SB364 (2006) $(\mathrm{au}=99 \%$ and $\mathrm{bp}=$ 96\%) (\#22).

The AMOVA analysis based on $\Phi \mathrm{PT}$ values indicated that most of the genetic diversity occurred within the population $(87 \%, P<0.023)$ while variability among the population only contributed $13 \%(P<0.023)$ (Table 4$)$. Statistically significant genetic differentiation was observed among the isolates.

\section{Discussion}

The genus Rhizoctonia is a diverse group of fungus which causes stem and root rot as well as foliar blights in many crops [1]. Rhizoctonia solani Kuhn, a ubiquitous soil borne basidiomycete, which causes diseases in many economically important crops like rice, potato, soybean, 
Table 1 Details of 41 Rhizoctonia solani isolates (38 test isolates and three control isolates with known AG group) with source, origin, year of isolation and morphological attributes

\begin{tabular}{|c|c|c|c|c|c|c|}
\hline Isolates $^{\mathrm{a}}$ & $\begin{array}{l}\text { Date of } \\
\text { Isolation }\end{array}$ & $\begin{array}{l}\text { Isolate } \\
\text { source }\end{array}$ & $\begin{array}{l}\text { Geographical } \\
\text { origin }\end{array}$ & State & Morphological description & $\begin{array}{l}\text { GenBank Accession } \\
\text { number of the ITS-rDNA }\end{array}$ \\
\hline$R Z \_D B 22$ & 2001 & DB & Box Butte & Nebraska & Light tan, sclerotia throughout agar & MT950064 \\
\hline$R Z \_D B 10$ & 2002 & DB & Box Butte & Nebraska & Brown & MT950066 \\
\hline$R Z \_D B 116$ & 2003 & DB & Scotts Bluff & Nebraska & Tan & MT950071 \\
\hline$R Z \_D B 222$ & 2004 & DB & Scotts Bluff & Nebraska & Light tan, aerial hyphae & MT950070 \\
\hline$R Z \_D B 305$ & 2005 & DB & Scotts Bluff & Nebraska & Brown & MT950067 \\
\hline$R Z \_D B 336$ & 2006 & $\mathrm{DB}$ & Scotts Bluff & Nebraska & Light brown & MT950077 \\
\hline$R Z \_D B 360$ & 2007 & DB & Scotts Bluff & Nebraska & Light brown & MT950078 \\
\hline$R Z \_D B 379$ & 2008 & DB & Scotts Bluff & Nebraska & Light brown & MT950079 \\
\hline$R Z \_D B 386$ & 2009 & DB & Scotts Bluff & Nebraska & Brown & MT950080 \\
\hline$R Z \_S B 37$ & 2000 & SB & Scotts Bluff & Nebraska & Dark tan, aerial hyphae, light brown sclerotia & MT950081 \\
\hline$R Z-S B 1$ & 2001 & SB & Scotts Bluff & Nebraska & Tan, aerial hyphae & MT950082 \\
\hline$R Z-S B 12$ & 2001 & SB & Scotts Bluff & Nebraska & Smooth, cream colored & MT950074 \\
\hline$R Z-S B 38$ & 2001 & SB & Scotts Bluff & Nebraska & Dark tan & MT950083 \\
\hline RZ-SB 39 & 2001 & SB & Scotts Bluff & Nebraska & Light tan, aerial hyphae & MT950069 \\
\hline$R Z-S B 16$ & 2002 & SB & Morrill & Nebraska & Dark tan, aerial hyphae & MT950085 \\
\hline$R Z-S B 23$ & 2002 & SB & Scotts Bluff & Nebraska & Tan, sclerotia throughout agar, flat & MT950086 \\
\hline RZ-SB 31 & 2002 & SB & Colorado & Colorado & Light tan, aerial hyphae & MT950063 \\
\hline RZ-SB 54 & 2003 & SB & Scotts Bluff & Nebraska & Tan, sclerotia throughout agar, flat & MT950087 \\
\hline RZ-SB 56 & 2003 & SB & Box Butte & Nebraska & Dark tan, aerial hyphae & MT950089 \\
\hline RZ-SB 59 & 2003 & SB & Scotts Bluff & Nebraska & Smooth, cream-colored, brown sclerotia & MT950090 \\
\hline$R Z-S B 188$ & 2004 & SB & Scotts Bluff & Nebraska & Tan, sclerotia throughout agar, flat & MT950091 \\
\hline$R Z-S B 194$ & 2004 & SB & Scotts Bluff & Nebraska & Cream colored, aerial hyphae, brown sclerotia & MT950068 \\
\hline$R Z-S B 202$ & 2004 & SB & Scotts Bluff & Nebraska & Smooth, light tan, aerial hyphae & MT950092 \\
\hline$R Z-S B 308$ & 2005 & SB & Scotts Bluff & Nebraska & Brown, aerial hyphae & MT950093 \\
\hline RZ-SB 310 & 2005 & SB & Scotts Bluff & Nebraska & Brown, aerial hyphae, sclerotia & MT950094 \\
\hline$R Z-S B 330$ & 2006 & SB & Scotts Bluff & Nebraska & Light tan, smooth & MT950076 \\
\hline$R Z-S B 332$ & 2006 & SB & Scotts Bluff & Nebraska & Dark tan, sclerotia & MT950095 \\
\hline$R Z-S B 349$ & 2006 & SB & Scotts Bluff & Nebraska & Dark tan, aerial hyphae, brown sclerotia & MT950073 \\
\hline$R Z-S B 358$ & 2007 & SB & Box Butte & Nebraska & Light tan, sclerotia, aerial hyphae & MT950096 \\
\hline$R Z-S B 359$ & 2007 & SB & Box Butte & Nebraska & Light tan, sclerotia, aerial hyphae, brown sclerotia & MT950065 \\
\hline$R Z-S B 364$ & 2007 & SB & Scotts Bluff & Nebraska & Dark tan, sclerotia & MT950063 \\
\hline$R Z-S B 373$ & 2008 & SB & Scotts Bluff & Nebraska & Dark tan, aerial hyphae & MT950098 \\
\hline$R Z-S B 374$ & 2008 & SB & Scotts Bluff & Nebraska & Cream colored & MT950088 \\
\hline$R Z-S B 375$ & 2008 & SB & Scotts Bluff & Nebraska & Brown, aerial hyphae & MT950099 \\
\hline RZ-SB 387 & 2009 & SB & Scotts Bluff & Nebraska & Dark tan, aerial hyphae & MT950075 \\
\hline$R Z-S B 388$ & 2009 & SB & Scotts Bluff & Nebraska & Brown, aerial hyphae, sclerotia & MT950100 \\
\hline$R Z-S B 389$ & 2009 & SB & Scotts Bluff & Nebraska & Dark tan, aerial hyphae & MT950101 \\
\hline$R Z-S B 391$ & 2010 & SB & Wyoming & Wyoming & Dark tan, sclerotia & MT950102 \\
\hline$R Z \_S B C 23$ & Unknown & SB & Imperial & Nebraska & AG group 2-2, ISG-IIIB & MT950103 \\
\hline$R Z \_S B C 28$ & Unknown & SB & Swink & Colorado & AG group 4 & MT950084 \\
\hline$R Z$ RBC51 & Unknown & SB & Montana & Montana & AG group 2-2, ISG-IV & MT950072 \\
\hline
\end{tabular}




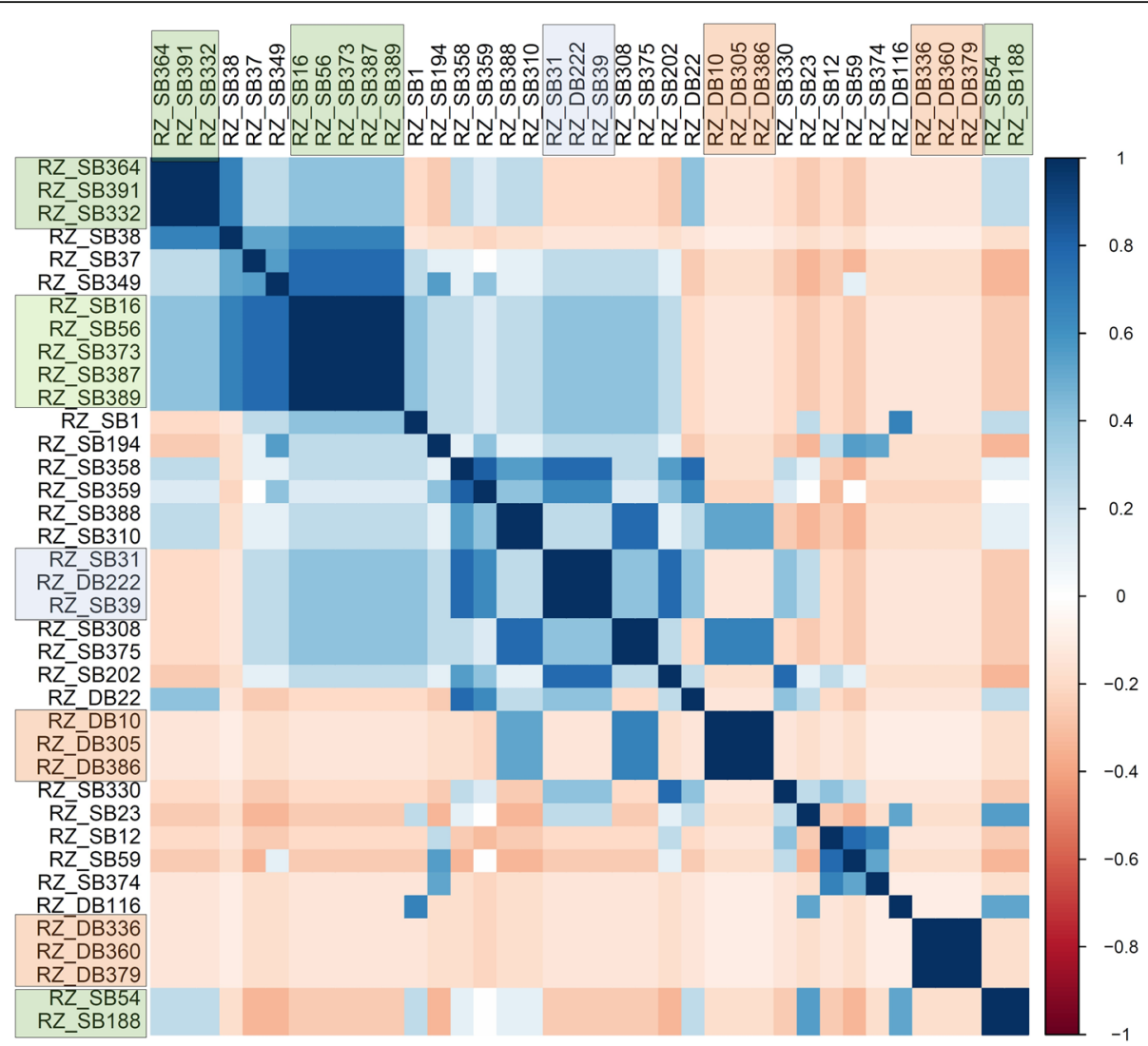

Fig. 2 Correlation of the isolates based on their morphological characteristics. The isolates showed crop specific crop correlation. Sugar beet isolates were correlated with sugar beets and dry beans were correlated with dry beans with one exception. Correlation between sugar beets was highlighted with green, orange shades which define correlation among sugarbeet and dry bean isolates respectively. Blue shades represent inter-correlation between the sugarbeet and dry bean isolates

corn, sugar beet and dry beans [22]. In the classical identification method, $R$. solani was characterized based on differences in pathogenicity, morphology, and physiology [18]. In this study, a total of 38 R. solani was isolated from sugar beet and dry bean in a time span of 10 years from different location of western Nebraska, USA (Table $1)$. Studies on cultural characteristics revealed that the colony color of the different $R$. solani isolates varied from cream-colored to brown, dark tan to light tan in PDA culture plates with the production of areal hyphae and sclerotia with dark to light brown color (Table 1). The results showed a close agreement with other works [11, 23, 24].

Results of the genetic analysis indicated a high degree of genetic diversity within the population (87\%). Both the population of sugar beet and dry bean have unique genetic makeup which can be observed from the marker genotypes. The sugar beet and dry bean isolates are mostly conserved within each crop and formed distinct clusters in dendrogram analysis with a few variations. Some of the sugar beet isolates also showed cross correlation with the isolates of dry bean (cluster 1 and cluster
3) (Fig. 4). This suggests relatedness among the population and wide pathogenicity spectrum of the group. AMOVA analysis also showed low variation among population (13\%) compared to within the population (87\%). PCA analysis and grouping based on marker genotypes also showed similar grouping patterns (Supplementary File: Fig. S1). It indicates, however, the origin of $R$. solani for sugar beet and dry bean are same but there is a certain degree of differentiation. The difference may have originated during the evolution and selection over pathogenicity. Similar results were observed form the studies of Dubey et al., (2012), where the $R$. solani isolates were independent or did not correspond to crops of origin [10, 25]. Sequence based phylogenetic study also showed wide diversity and independent nature of the pathogens. The isolated pathogens grouped into clusters without corresponding to their host crop (Fig. 5).

Morphological classification of the isolates showed high level of differentiation among the isolates from sugar beet and dry bean. Grouping based on only morphological traits showed correlation within the isolates 


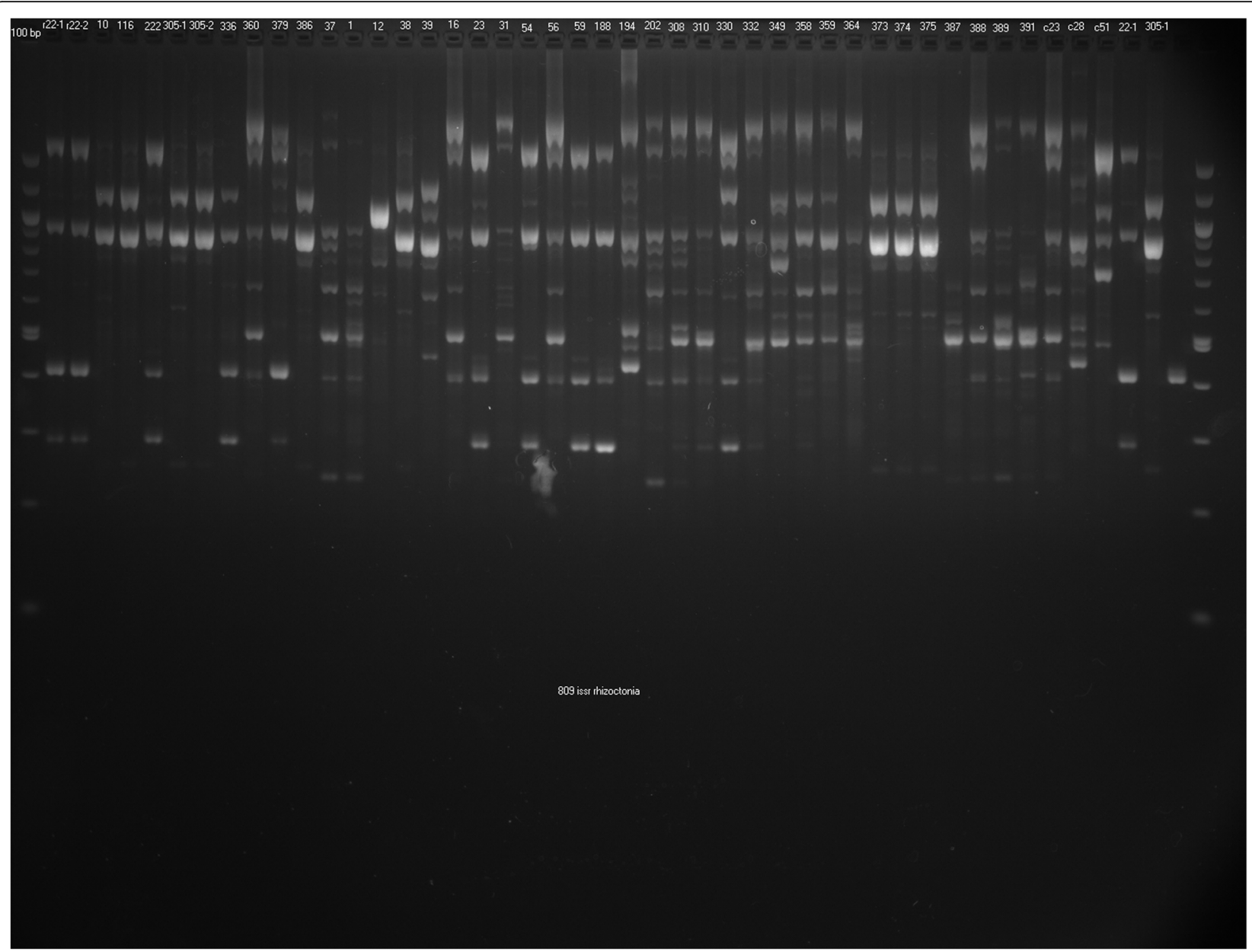

Fig. 3 DNA marker profiles of Rhizoctonia solani isolates from sugar beets and dry beans with ISSR primer UBC809. Sugar beet and dry bean isolates are designated by RZ_SB and RZ_DB followed by a number

of same population (Fig. 2). However, marker-based analysis showed certain degree of cross-correlations among the populations. Grouping of the isolates based on location and year highlighted stimulating facts. High bootstrap (97\%) and $p$-value (99\%) between the isolates $\mathrm{RZ}_{-}$ SB374 and RZ-375 indicate the same genetic origin based on the fact they were collected in same year (2008) and from same place (Scottsbluff) (Fig. 4). It also indicates the chances of them being in the same pathovar group which couldn't be morphologically differentiated. Isolates from consecutive years also showed a high degree of genetic similarity defining the chances of same pathogens infecting the fields in the successive year. This also indicates their inoculum may have been present in the crop residues or soil from previous year, which are left untreated and produced the infection. Isolates like RZ_SB194 showed 100\% bootstrap identity with control strain RZ_SBC28 of sugar beet (au $=100 \%$ ). This suggests genetic similarity and possibility of RZ_194 belonging to AG-Group 2-2 IIIB, which is a major anastomosis group responsible for sugar beet crown and root rot [26]. Isolates RZ_SB388 and control strain RZ_ $\mathrm{SBC} 23$ also showed genetic resemblance but with low bootstrap probability value $(56 \%)$ and was not statistically significant (84\%) (\#13) (Fig. 4). It can be concluded, though there is some degree of similarity, they are totally different pathovars.

The location-based grouping of the isolates based on marker profile showed random distribution. Scottsbluff with the highest number of isolates showed a correlation with all the isolates from other places and among themselves. Isolates from the Scottsbluff showed a high degree of similarity with the isolates of Box Butte, Morril, Imperial. Although sampling of this study was uneven with respect to crop and collection. But, there was a mixed genetic population as noticed in cluster analysis. Isolates distributed independently of their geographical locations. Among the 31 isolates from Scottsbluff, there were four distinct divisions (Fig. 6). Several studies reported similar uneven relationship or no correlation 
Table 2 List of 19 ISSR markers used for the study

\begin{tabular}{llll}
\hline ISSR primer name & Sequence (5'-3') & Marker size (bp) & Number of polymorphic markers \\
\hline UBC808 & AGAGAGAGAGAGAGAGC & $400-2000$ & 27 \\
UBC809 & AGAGAGAGAGAGAGAG & $200-2000$ & 26 \\
UBC811 & GAGAGAGAGAGAGAGAC & $400-3000$ & 25 \\
UBC812 & GAGAGAGAGAGAGAGAA & $300-2000$ & 15 \\
UBC816 & CACACACACACACACAT & $400-2000$ & 18 \\
UBC818 & CACACACACACACACAG & $300-2000$ & 17 \\
UBC821 & GTGTGGTGTGGTGT & $400-3000$ & 23 \\
UBC828 & TGTGTGGTGGTGTGA & $400-3000$ & 24 \\
UBC835 & AGAGAGAGAGAGAGAGYC & $200-3000$ & 21 \\
UBC842 & GAGAGAGAGAGAGAGAYG & $100-1500$ & 19 \\
UBC855 & ACACACACACACACACYT & $300-2000$ & 17 \\
UBC856 & ACACACACACACACACYA & $400-3000$ & 15 \\
UBC857 & ACACACACACACACACYG & $300-2000$ & 19 \\
UBC864 & ATGATGATGATGATGAT & $300-2000$ & 23 \\
UBC880 & GGAGAGGAGAGGAGA & $200-2000$ & 22 \\
UBC884 & HBHAGAGAGAGAGAGA & $200-3000$ & 20 \\
UBC888 & BDBCACACACACACACA & $200-2000$ & 28 \\
UBC889 & DBDACACACACACACAC & $200-3000$ & 21 \\
UBC890 & VHVGTGTGGTGTGGT & $300-2000$ & \\
\hline
\end{tabular}

between the place of origin and isolates of $R$. solani $[10$, 25, 27, 28].

Relying only on morphological characteristics often may results in misidentification as the pathogens belonging to same group with similar morphological feature may differ in pathogenicity. In this study, we observed morphological correlation showed a distinct difference between the isolates of sugar beet and dry bean, while genetic diversity showed certain degree of cross correlation between the ioslates of sugar beet and dry bean. Therefore, using morphological traits as sole identification method can result in biased grouping when the population are distinct or unique in their genetic makeup. Thus, this study proved that marker

Table 3 Allele diversity within the population

\begin{tabular}{lllllllll}
\hline Pop & & $\mathbf{N}$ & $\mathrm{Na}$ & $\mathrm{Ne}$ & $\mathbf{I}$ & $\mathrm{He}$ & $\mathrm{uHe}$ & $\% \mathbf{P}$ \\
\hline Pop1 & Mean & 8.000 & 0.980 & 1.269 & 0.240 & 0.159 & 0.169 & 48.35 \\
& SE & 0.000 & 0.050 & 0.018 & 0.014 & 0.010 & 0.010 & \\
Pop2 & Mean & 30.000 & 1.858 & 1.249 & 0.280 & 0.167 & 0.170 & 92.88 \\
& SE & 0.000 & 0.026 & 0.014 & 0.010 & 0.008 & 0.008 & \\
Pop3 & Mean & 3.000 & 0.891 & 1.259 & 0.235 & 0.156 & 0.187 & 43.26 \\
& SE & 0.000 & 0.050 & 0.017 & 0.014 & 0.009 & 0.011 & \\
\hline
\end{tabular}

${ }^{*} \mathrm{Na}=$ No. of Different Alleles; $\mathrm{Ne}=$ No. of Effective Alleles $=1 /\left(\mathrm{p}^{2}+\mathrm{q}^{2}\right) ; \mathrm{I}=$ Shannon's Information Index $=-1 *(p * \operatorname{Ln}(p)+q * \operatorname{Ln}(q)) ; \mathrm{He}=$ Expected Heterozygosity $=2 * p^{*} q ; u H e=$ Unbiased Expected Heterozygosity $=(2 \mathrm{~N} /(2$ $\mathrm{N}-1)) *$ He [for Diploid Binary data and assuming Hardy-Weinberg Equilibrium, $\mathrm{q}=(1-\text { Band Freq. })^{0.5}$ and $\left.p=1-\mathrm{q}\right]$ information in addition to morphological traits gave a better identification and characterization of intra and intergenic genetic variations. For differentiation and characterization of the $R$. solani from sugar beet and dry bean, ISSR marker was found suitable with the morphological features. This method can give a comprehensive estimation of genetic diversity of polyphyletic isolates where anastomosis or morphological features were not sufficient. Identification and proper categorization of the pathogen will be helpful in designing integrated disease management guidelines for sugar beet and dry beans of mid western America.

\section{Conclusion}

There were no significant genetic and morphological differences in both sugar beet and dry bean isolates which were collected over 10 years in Nebraska Panhandle. This suggested that possibly there was no significant genetic mutations occurred during these years, which would otherwise cause challenges to existing disease management strategies. Majority of the isolates from sugar beet showed nearby association within the population. However, ISSR-DNA marker-based similarity among a few isolates of both the crops suggesting their broad pathogenicity. This may need to be confirmed by cross-pathogenicity tests where the same isolate is used to infect both sugar beet and dry bean. Identification and characterization of the 


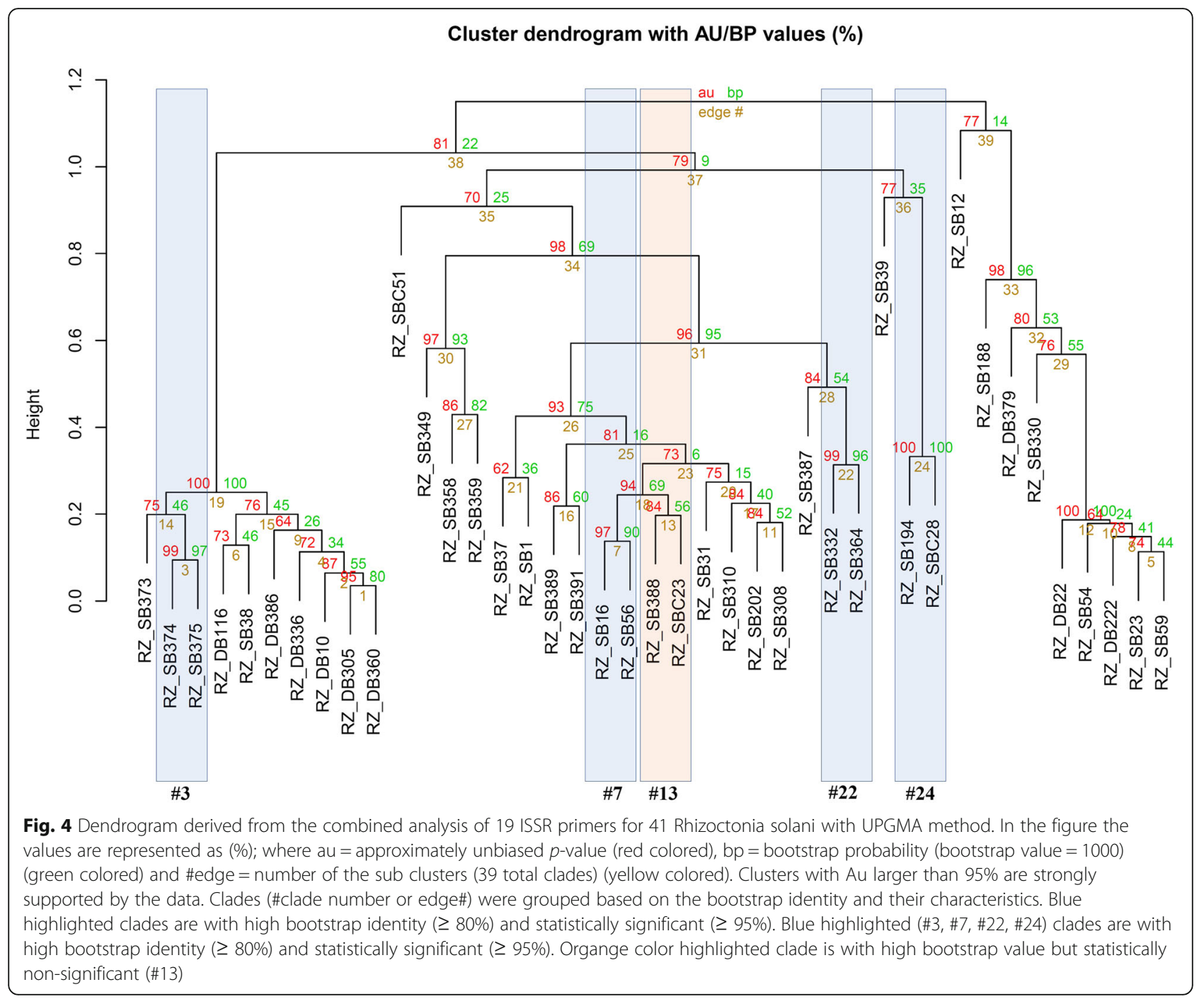

pathogen may be helpful in designing integrated disease management guidelines for sugar beet and dry bean of mid western Nebraska.

\section{Methods}

\section{Fungal isolates}

Infected plants were collected from different regions of western Nebraska (Fig. 1a - b). A total of $38 R$. solani were isolated from the collected samples and used for this study. Twenty-nine were from sugar beet and nine isolates were from dry bean. Isolates were recovered from symptomatic diseased sugar beet and dry bean roots. For isolation, surface sterilized plant material was platted on potato dextrose agar (PDA) medium containing streptomycin antibiotic to reduce the opportunistic bacterial growth. Culture plates were incubated at $26^{\circ} \mathrm{C}$. Isolates were identified microscopically, and morphological features were recorded (Table. 1) [29]. Three control strains of $R$. solani of sugar beet (RZ_SBC23, RZ_SBC28, and RZ-SBC51) from Nebraska, Montana and Colorado were collected from Dr. Linda E. Hanson (USDA - ARS Sugarbeet and Bean Research, East

Table 4 Hierarchical distribution of genetic diversity among the population of $R$. solani from sugar beet and dry beans

\begin{tabular}{llllllll}
\hline Source & df & SS & MS & Estimated Variation & \% of variation & ФPT $^{\mathbf{a}}$ & $\mathbf{p}$ \\
\hline Among Pops & 2 & 219.93 & 109.97 & 7.29 & $13 \%$ & 0.14 & $<0.023$ \\
Within Pops & 38 & 1787.53 & 47.04 & 47.04 & $87 \%$ & $100 \%$ & \\
Total & 40 & 2007.46 & & 54.33 & &
\end{tabular}




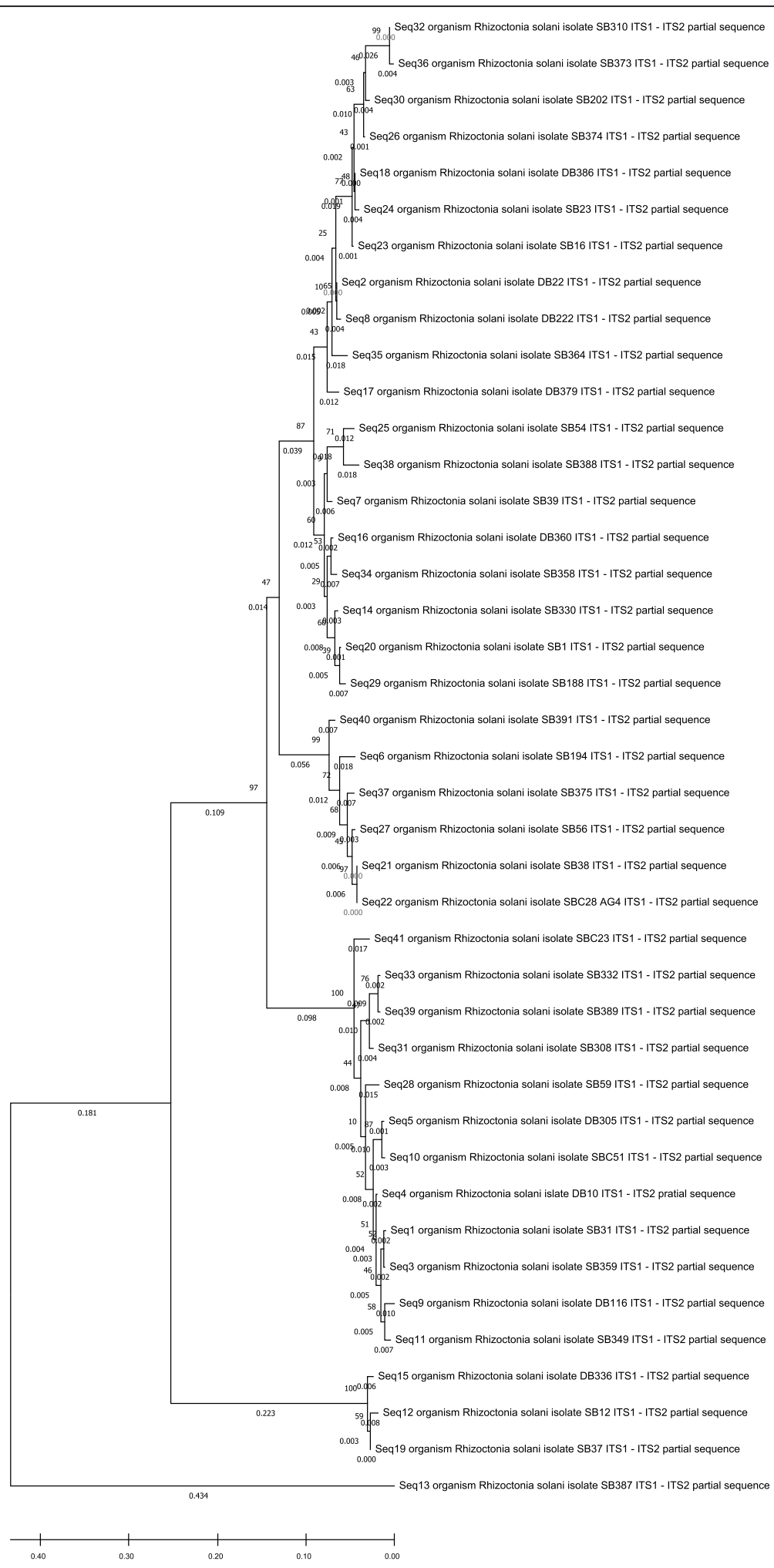

Fig. 5 (See legend on next page.) 
(See figure on previous page.)

Fig. 5 The evolutionary history of the 41 isolates based on ITS-rDNA sequences was inferred using the Neighbor-Joining method. The optimal tree with the sum of branch length $=1.62$ is shown. The percentage of replicate trees in which the associated taxa clustered together in the bootstrap test (1000 replicates) are shown next to the branches (next to the branches). The evolutionary distances were computed using the Jukes-Cantor method and are in the units of the number of base substitutions per site

Lansing, Michigan) (Table 1). These strains were used for ISSR marker analysis to compare the genetic relatedness among the isolates and with known AG grouping. Population 1, 2, and 3, were used in this report to indicate the group of 29 sugar beet isolates, 9 dry bean isolates, and 3 control strains.

\section{Validation of isolates identify}

Isolated pathogens were taxonomically validated by sequencing ITS1 (TCCGTAGGTGAACCTGCGG) and ITS2 (GCTGCGTTCTTCATCGATGC) region. Identity was confirmed by sequence similarity search with NCBI Blast with $\mathrm{nr} / \mathrm{nt}$ nucleotide database. The sequences were submitted to GenBank for accession number (MT950063MT950103) and further references (Table 1).

Pathogenicity test was done in greenhouse following established methods being used in Harveson lab using the isolated fungal culture of the nine RZ_DB isolates on the host plant dry bean and 29 RZ_SB on the host plant sugar beet.

\section{DNA extraction}

For DNA extraction fresh fungal culture was used. Five $1 / 4 \times 1 / 4$ inch plugs of agar were placed into $50 \mathrm{ml}$ of sterile
PDB and grown for 5 days at $26^{\circ} \mathrm{C}$. After the incubation period, mycelia were harvested by filtration through cheesecloth. The collected mycelia were lyophilized with liquid nitrogen and grounded into a fine powder with mortar and pestle. The powder was transferred to $50 \mathrm{ml}$ conical tubes containing $15 \mathrm{ml}$ of CTAB extraction buffer (2\% CTAB, 1.4 M NaCl, 20 mM EDTA, pH 8.0, 0.1 M Tris, $\mathrm{pH} 8.0,0.4 \%$ B-mercaptoethanol) preheated to $65^{\circ} \mathrm{C}$. The samples were then incubated in a $65^{\circ} \mathrm{C}$ water bath for $1 \mathrm{~h}$, with mixing at an interval of every $10 \mathrm{~min}$. Samples were cooled for $10 \mathrm{~min}$ and $20 \mathrm{ml}$ of chloroform/isoamyl alcohol (24:1) was added and mixed with each tube. The tubes were centrifuged at $3500 \mathrm{rpm}$ for $20 \mathrm{~min}$ at $15^{\circ} \mathrm{C}$. The aqueous layer was transferred to a new tube and a double volume of chilled $95 \%$ ethanol was added to precipitate the DNA. The tubes were centrifuged at $3500 \mathrm{rpm}$ for $1 \mathrm{~min}$ and the supernatant was discarded. Pellets were washed with chilled $70 \%$ ethanol. After all, ethanol was removed the dry DNA pellet was suspended in $1 \mathrm{ml}$ of TE buffer $(10 \mathrm{mM}$ Tris- $\mathrm{HCl}$ and 1 mM EDTA, pH 8.0) and treated with 5 ul of RNAse (10 $\mathrm{mg} / \mathrm{ml}$ ) at room temperature for $1 \mathrm{~h}$. DNA was quantified using the mini-gel method [30] that compares band intensities with a standard lambda/HindIII DNA marker

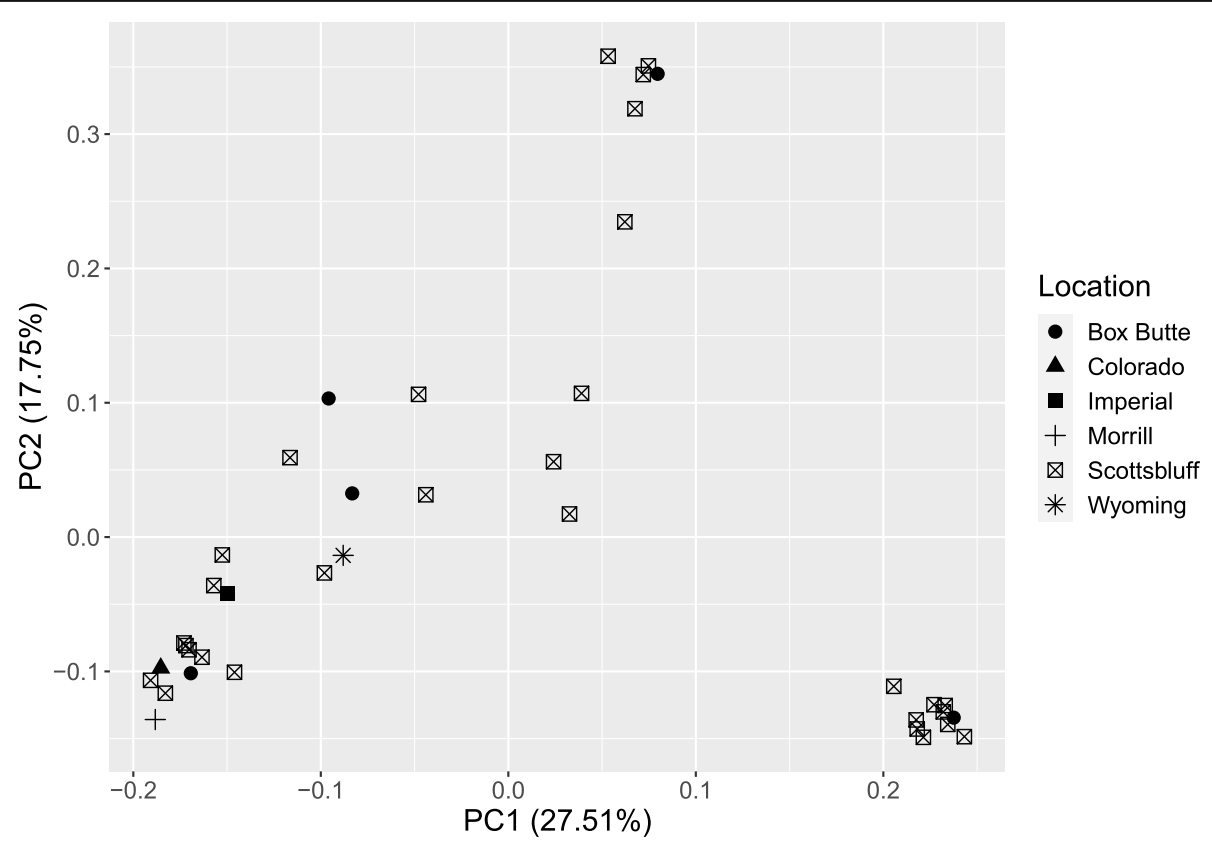

Fig. 6 Location-based distribution of the R. solani isolates based on marker data 
(Gibco BRL, Betheseda, MD) in a $0.8 \%$ agarose gel. DNA was diluted to a concentration of $25-50 \mathrm{ng} / \mathrm{ul}$ for use in a polymerase chain reaction (PCR).

\section{PCR amplification of ISSR}

The 50 UBC primers screened in this study were obtained from Eurofins Genomics (Huntsville, Alabama). Nineteen (Table 2) were selected for analysis based on amplification profile (band intensity, quality, and reproducibility in at least two independent replications) on two random isolates. PCR amplification was performed in a $25 \mu$ l reaction mixture containing Promega $5 x$ Green GoTaq Flexi Buffer, $2 \mathrm{mM} \mathrm{MgCl}_{2}, 100 \mu \mathrm{m}$ of dNTPs, $0.24 \mu \mathrm{M}$ primer, $50-100 \mathrm{ng}$ DNA, and 1 unit of Taq polymerase. The cyclic reaction was set at initial denaturation at $94{ }^{\circ} \mathrm{C}$ for $30 \mathrm{~s}$, annealing at $50^{\circ} \mathrm{C}$ for $45 \mathrm{~s}$, and an elongation at $72^{\circ} \mathrm{C}$ for $2 \mathrm{~min}$ ( 45 cycles). Final elongation was performed for $10 \mathrm{~min}$. The PCR was completed on an Applied Biosystems Thermocycler 2720. PCR products were separated electrophoretically in $2 \%$ agarose gels including $0.5 \mu \mathrm{g} / \mathrm{ml}$ ethidium bromide and bands were visualized in the gel-doc system (Biorad, USA). ISSR gels were photographed using FOTO Analyst Express Electronic Imaging System (Fotodyne, Inc). Marker size range was determined by comparison with a 100 bp DNA ladder (New England BioLabs). When scoring the gels, a marker locus was considered polymorphic if the band was not present in every isolate. Only clear DNA bands that were reproducible were scored. ISSR marker loci were designated by primer name.

\section{Data analysis}

A correlation matrix and dendrogram were prepared with unweighted pair group method with arithmetic mean (UPGMA) method to distinguish the isolates based on morphological characteristics. The categorical data of morphological traits were converted into a 0,1 matrix based on presence and absence of that. The dendrogram (method = UPGMA) and correlation plot ( method $=$ Pearson correlation) were prepared using $\mathrm{R}$ statistical software (package: pvclust and corrplot). Dominant polymorphic ISSR markers were scored based on presence and absence with 0 (absent) - 1 (present) matrix. Cluster analysis was carried out using UPGMA method and dendrogram was created by using $\mathrm{R}$ statistical software with a bootstrap value of 1000 with package pvclust [31]. The package was used to compute two values: an approximately unbiased (AU) $p$-value based on multi-step multiscale bootstrap resampling procedure [32] and a bootstrap probability (BP) $p$-value from ordinary bootstrap resampling [33]. A significance threshold of $\alpha=0.05$ (95\% confidence interval) was used in this approach. For a cluster with AU $p$-value $>0.95$ (95\%), the hypothesis that "the cluster does not exist" is rejected with significance level 0.05 . The percentage of polymorphic loci $(\mathrm{P})$, Shannon's diversity index $(I)$ and Nei's gene diversity were calculated to estimate the genetic variation among the isolates using GenAlex 6.5 software [34]. Genetic differentiation among populations was estimated by pairwise values of $\phi_{\mathrm{PT}}$. Analysis of molecular variance (AMOVA) was used to compute the genetic variation among and within the population. AMOVA calculations were performed in GenAlex 6.5. Principle component analysis was used to determine genetic differentiation among the isolates of different region using $\mathrm{R}$ statistical software (Package: FactoMiner, factoextra, and ggplot2). Morphological and genetic traits were correlated with R-stat to determine the diversity among and within the isolates of sugar beets and dry beans (Package: corrplot). For phylogenetic analysis, a neighbor-joining tree was constructed using bootstrapping method (1000) and evolutionary distance was computed using Jukes-Cantor method MEGA-X software.

\section{Supplementary Information}

The online version contains supplementary material available at https://doi. org/10.1186/s12866-020-02026-9.

Additional file 1: Figure S1. Principal component analysis based on (a) Morphological traits, (b) Marker profile. Morphological traits doesn't able to completely distinguish between the two population and they formed one big cluster while marker profile showed to distinct group for two populations.

Additional file 2: Table S1. Correlation Matrix_Morphology.

\section{Abbreviations}

AMOVA: Analysis of molecular variance; RZ_DB: Rhizoctonia_Dry Bean; RZ_SB: Rhizoctonia_Sugar Beet; RZ_SBC: Rhizoctonia_Sugar Beet Control; bp: Base pair

\section{Acknowledgments}

Authors would like to acknowledge Dr. Lind E. Hanson, USDA Research Scientist, for providing the three control strains for $R$. solani with known AG group.

\section{Authors' contributions}

D.K.S. and R.M.H conceived the idea and design of the study. S.D. and T.P-H performed experiment, data analysis and wrote the manuscript. K.A.N. purified and maintained fungal culture. B.M. contributed in sequence data. D.K.S. and R.M.H conceived the project idea, designed experiments, inferred experimental data, reviewed \& edited extensive, and prepared the final draft. All authors have read and approved the final manuscript.

\section{Funding}

The project was partially supported by 'Research State Aided' internal funds: 21-6243-1001 to D. K. Santra and 21-6243-1006 to R. M. Harveson.

Harveson's fund was used for isolates collections from the fields, purification of isolates in the field and maintenance, morphological characterization and greenhouse pathogenicity tests. Santra's fund was used for molecular marker analyses (ISSR marker and ITS-rDNA sequencing).

Availability of data and materials

All data generated or analyzed during this study are included in this published article [and its supplementary information files].

Ethics approval and consent to participate

Not applicable. 


\section{Consent for publication}

Not applicable.

\section{Competing interests}

The authors declare that they have no competing interests.

Received: 12 September 2020 Accepted: 28 October 2020 Published online: 17 November 2020

\section{References}

1. Ogoshi A. Introduction - the genus Rhizoctonia. In: Sneh B, Jabaji-Hare S, Neate SM, Dijst G, editors. Rhizoctonia species: taxonomy, molecular biology, ecology, pathology and disease control. Dordrecht: Springer Netherlands: 1996 p. 1-9.

2. Plyler-Harveson T, Harveson R, Nielsen AK, Santra D. Genetic characterization of Rhizoctonia Solani population from sugar beet and dry bean. In: 2011 APS-IPCC meeting. Honolulu: American Phytopathological Society; 2011. p. 152.

3. Wendels C, Jacobson B, Harveson R. Rhizoctonia root and crown rot. In: Harveson R, Harveson L, Hein G, editors. Compedium of beet diseases and pests; 2009. p. 33-6.

4. Liu B, Klein R. Root rot caused by Rhizoctonia Solani on soybean. University of Nebraska-Lincoln CROPWATCH; 2012

5. Hanson LE, McGrath JM. Rhizoctonia seedling disease on sugar beet. Int Sugar J. 2011:113:584-9.

6. Harveson RM, Smith JA. Improving root health and yield of dry beans in the Nebraska panhandle with a new technique for reducing soil compaction. Plant Dis. 2005;89:279-84. https://doi.org/10.1094/PD-89-0279.

7. Ogoshi A. Ecology and pathogenicity of anastomosis and intraspecific groups of Rhizoctonia Solani Kuhn. Annu Rev Phytopathol. 2003;25:125-43.

8. Carling DE. Grouping in Rhizoctonia Solani by Hyphal anastomosis reaction. In: Rhizoctonia species: taxonomy, molecular biology, ecology, pathology and disease control. Dordrecht: Springer Netherlands; 1996. p. 37-47.

9. Carling DE, Kuninaga S, Brainard KA. Hyphal anastomosis reactions, rDNAinternal transcribed spacer sequences, and virulence levels among subsets of Rhizoctonia solani anastomosis Group-2 (AG-2) and AG-BI. Phytopathology. 2002;92:43-50

10. Dubey SC, Tripathi A, Upadhyay BK. Molecular diversity analysis of Rhizoctonia solani isolates infecting various pulse crops in different agroecological regions of India. Folia Microbiol (Praha). 2012;57:513-24.

11. Jaaffar AKM, Paulitz TC, Schroeder KL, Thomashow LS, Weller DM. Molecular characterization, morphological characteristics, virulence, and geographic distribution of Rhizoctonia spp. in Washington state. Phytopathology. 2016; 106:459-73.

12. TingDan L, ShiWen P, ZongHua W, GuoDong L. Genetic diversity analysis of Rhizoctonia solani populations from Fujian using inter-simple sequence repeats (ISSR) technique. Acta Phytopathol Sin. 2010;40:186-94.

13. Wang L, Liu LM, Wang ZG, Huang SW. Genetic structure and aggressiveness of Rhizoctonia solani AG1-IA, the cause of sheath blight of Rice in southern China. J Phytopathol. 2013;161:753-62.

14. Ceresini PC, Shew HD, Vilgalys RJ, Cubeta MA. Genetic diversity of Rhizoctonia solani AG-3 from potato and tobacco in North Carolina. Mycologia. 2002;94:437-49.

15. Shu CW, Zou CJ, Chen JL, Tang F, Yi RH, Zhou EX. Genetic diversity and population structure of Rhizoctonia solani AG-1 IA, the causal agent of rice sheath blight, in South China. Can J Plant Pathol. 2014;36:179-86.

16. Taheri P, Gnanamanickam S, Höfte M. Characterization, genetic structure, and pathogenicity of Rhizoctonia spp. associated with Rice sheath diseases in India. Theor Popul Biol. 2007;97:373-83.

17. Bernardes-de-Assis J, Storari M, Zala M, Wang W, Jiang D, ShiDong L, et al. Genetic structure of populations of the Rice-infecting pathogen Rhizoctonia solani AG-1 IA from China. Phytopathology. 2009;99:1090-9. https://doi.org/ 10.1094/PHYTO-99-9-1090.

18. Sharma M, Gupta SK, Sharma TR. Characterization of variability in Rhizoctonia solani by using morphological and molecular markers. J Phytopathol. 2005:153:449-56.

19. Goswami SK, Singh V, Kashyap PL. Population genetic structure of Rhizoctonia solani AG1IA from rice field in North India. Phytoparasitica. 2017;45:299-316
20. Zhou QX, Hwang SF, Fu HT, Strelkov SE, Gossen BD. Genetic variation of Rhizoctonia solani isolates from canola in Alberta, Canada. Can J Plant Sci. 2014;94:671-81.

21. Zheng L, Shi F, Hsiang T. Genetic structure of a population of Rhizoctonia solani AG 2-2 IIIB from Agrostis stolonifera revealed by inter-simple sequence repeat (ISSR) markers. Can J Plant Pathol. 2013;35:476-81.

22. Sneh B, Burpee L, Ogoshi A. Identification of Rhizoctonia species. APS press; 1991.

23. Takashi N, Tadao U. Ecological and morphological characteristics of the sclerotia of Rhizoctonia solani Kühn produced in soil. Soil Biol Biochem. 1978;10:471-8

24. Desvani SD, Lestari IB, Wibowo HR, Poromarto SH. Morphological characteristics and virulence of Rhizoctonia solani isolates collected from some rice production areas in some districts of Central Java; 2014. 20068-120068-6.

25. Stodart BJ, Harvey PR, Neate SM, Melanson DL, Scott ES. Genetic variation and pathogenicity of anastomosis group 2 isolates of Rhizoctonia solani in Australia. Mycol Res. 2007;111:891-900.

26. Strausbaugh CA, Eujayl IA, Panella LW, Hanson LE. Virulence, distribution and diversity of Rhizoctonia solani from sugar beet in Idaho and Oregon. Can J Plant Pathol. 2011:33:210-26.

27. Fiers M, Edel-Hermann V, Héraud C, Gautheron N, Chatot C, Le Hingrat $Y$, et al. Genetic diversity of Rhizoctonia solani associated with potato tubers in France. Mycologia. 2011;103:1230-44.

28. Zhou Q-X, Chang K-F, Hwang S-F, Strelkov SE, Gossen BD, Chen Y-Y. Pathogenicity and genetic diversity of Rhizoctonia solani isolates from lupin and other crops in Alberta, Canada. Can J Plant Pathol. 2009:31:340-7.

29. Harveson RM. Identifying and distinguishing seedling and root rot diseases of sugar beets. Plant Heal Prog. 2006;7:39.

30. Sambrrok J, Fritsch E, Maniatis T. Molecular cloning: a laboratory manual. 2nd ed: Cold Spring Harbor Laboratory Press; 1989.

31. Suzuki R, Shimodaira H. Pvclust: an R package for assessing the uncertainty in hierarchical clustering. Bioinformatics. 2006;22:1540-2.

32. Shimodaira $\mathrm{H}$. Approximately unbiased tests of regions using multistepmultiscale bootstrap resampling. Ann Stat. 2004;32:2616-41. https://doi.org/ 10.1214/009053604000000823.

33. Efron B, Halloran E, Holmes S. Bootstrap confidence levels for phylogenetic trees. Proc Natl Acad Sci U S A. 1996:93:13429-34. https://doi.org/10.1073/ pnas.93.23.13429.

34. Peakall R, Smouse PE. GenAlEx 6.5: genetic analysis in excel. Population genetic software for teaching and research--an update. Bioinformatics. 2012 28:2537-9.

\section{Publisher's Note}

Springer Nature remains neutral with regard to jurisdictional claims in published maps and institutional affiliations.

Ready to submit your research? Choose BMC and benefit from:

- fast, convenient online submission

- thorough peer review by experienced researchers in your field

- rapid publication on acceptance

- support for research data, including large and complex data types

- gold Open Access which fosters wider collaboration and increased citations

- maximum visibility for your research: over $100 \mathrm{M}$ website views per year

At BMC, research is always in progress.

Learn more biomedcentral.com/submissions 